\title{
Central statistical monitoring in clinical trials
}

\author{
Amy A Kirkwood*, Allan Hackshaw \\ From Clinical Trials Methodology Conference 2011 \\ Bristol, UK. 4-5 October 2011
}

\section{Background}

On-site monitoring is a common but time-consuming and expensive activity, with little evidence that it is worthwhile. Centralised statistical monitoring (CSM) is a much cheaper alternative, where data checks are performed by the co-ordinating centre, reducing the need to visit every site. Although some publications have outlined possible methods, few have applied them to data from real clinical trials.

\section{Methods}

R-programs were developed to check data at either the patient or site level, for fraud or data errors. These included finding anomalous data patterns, digit preference, rounding, incorrect dates (eg weekends/holidays), values of variables too close or too far from the means, odd correlation structures and extreme values or variances. We applied these to 3 trials: (i) where data had already been checked, (ii) an ongoing trial where our findings could be checked in real-time, and (iii) where data errors and fake patients were created.

\section{Findings}

The programs were designed to be run automatically and produce simple tables or figures. Few errors were detected in the trial where data had already been checked (as expected). Most data errors were found in the two other trials. The programs were able to detect data errors, as well as fabricated patients that we generated to have values that were too close to the multivariate mean (fig. 1). They also detected centres that had too few or too many serious adverse events (fig. 2). It might be difficult to reliably apply some of the programs to centres with few patients. Several patients that were fabricated were not detected because the data did not follow the assumptions used by the R-programs, or the number of fabricated patients within a centre was too

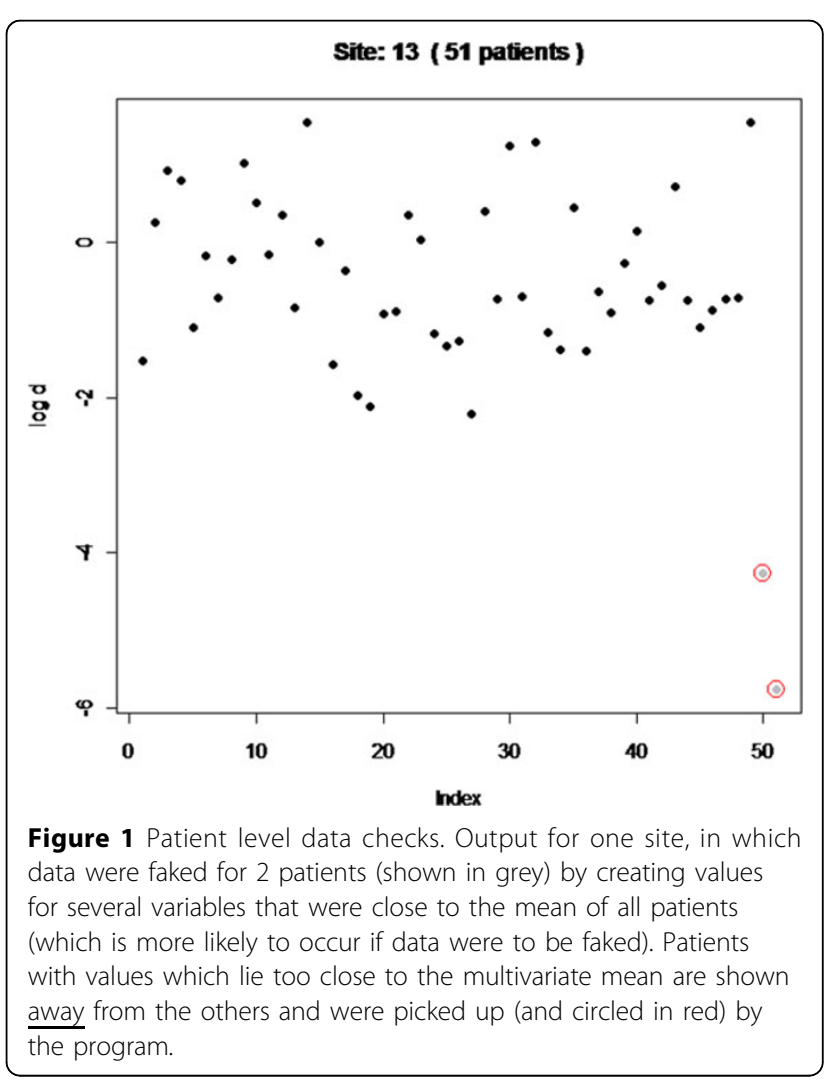

small. Examples of the different output produced, including easy-to-read diagrams and how they are interpreted, could be shown and discussed, along with their strengths and limitations.

\section{Conclusions}

CSM appears to be a cost-effective and worthwhile alternative to on-site monitoring. It can identify incorrect patient data, or centre where the data considered together is too different to all other sites and therefore should be reviewed. However, more research is needed 


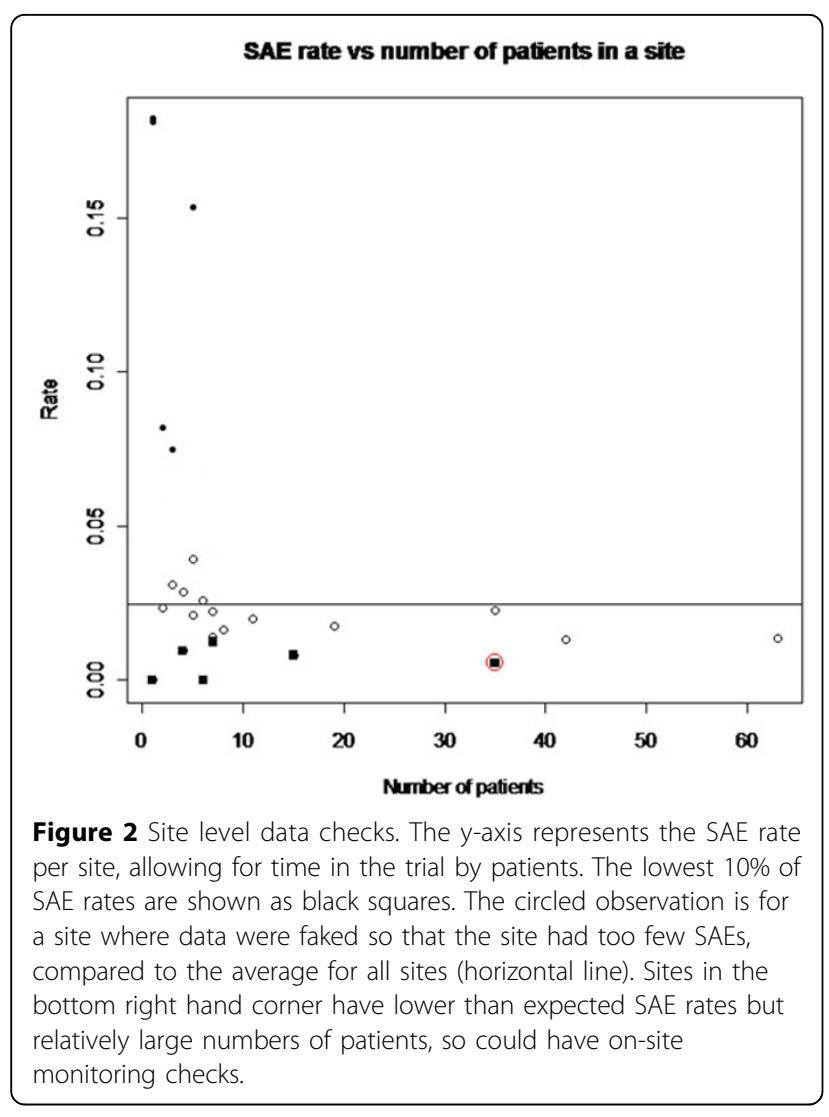

to identify which situations CSM does not work well in.

Published: 13 December 2011

doi:10.1186/1745-6215-12-S1-A55

Cite this article as: Kirkwood and Hackshaw: Central statistical monitoring in clinical trials. Trials 2011 12(Suppl 1):A55.

\section{Submit your next manuscript to BioMed Central} and take full advantage of:

- Convenient online submission

- Thorough peer review

- No space constraints or color figure charges

- Immediate publication on acceptance

- Inclusion in PubMed, CAS, Scopus and Google Scholar

- Research which is freely available for redistribution

Submit your manuscript at www.biomedcentral.com/submit
C Biomed Central 